\title{
GERÊNCIANDO SEM RECORRER A SOLUÇÕES PALIATIVAS: um Programa Totalmente Integrado para Criar $e$ Manter o Sucesso Organizacional
}

\section{RALPH H. KILMANN}

Rio de Janøiro, Editora Qualitymark, 1991, 263 páginas. Traduçäo brasileira de "Managing Beyond the Quick Fix" por Associaçăo Alumni - Elenice Mazzili, Janice M. Louzada e Lúcia Faria Silva.

Por Thomas Wood, Jr, Engenheiro Químico pela UNICAMP, Mestrando em Administração de Empresas pela EAESPIFGV e Profissional do Setor Fibras e Polimeros da Rhodia S.A.

$\mathrm{E}$ m uma edição de 1986, a revista Business Week publicou um artigo de capa intitulado "Business fads: what's in and out". Falava-se da enxurrada de conceitos e teorias que assolava as empresas. À época, conceitos como Cultura Corporativa, Espírito Empreendedor e Alianças Estratégicas eram considerados "in". Os nomes "quentes" eram Tom Peters, Gifford Pinchot III e o veterano Peter Drucker. Por outro lado, Sinergia, Teoria $Z$ e Gerenciamento por Objetivos, fả eram considerados "out" . Em outra ediçã̃o, bem mais recente, de agosto de 1992, a mesma revista voltou ao assunto com outra reportagem de capa, intitulada "Management 's New Gurus and what they 're telling bussiness". As idéias, agora na moda, são: Arquitetura Organizacional, "Learning Organization" e "Reengineering". Por trás destas idéias estão nomes antes pouco conhecidos como David Nadler, Peter Senge e Michael Hammer.

As reportagens da Business Week, assim como o substancial crescimento que o mercado de livros sobre administraçăo tem experimentado, refletem o interesse que 0 tema ganhou nos últimos anos. Ler sobre novos conceitos gerenciais, ou sobre mudanças nas organizações, tornouse uma obrigação para todo o gerente ou executivo que se preze. Por trás deste fenômeno editorial está a preocupaçăo com a compreensão dos fenômenos que ocorrem no mundo organizacional.

Quanto à qualidade do material disponível, existe de tudo. Os editores estăo visivelmente preocupados com o apelo comercial e os livros são, em geral, de fácil leitura. Após ter em mãos vários destes livros, nẫo é difícil notar que eles seguem um certo padrăo: os autores geralmente realizam um sintese razóavel do material existente sobre o tema abordado; criam, ou recriam, um conceito antigo ou uma metodologia de intervenção; dão-lhe uma marca registrada ou grife; prestam consultoria para a AT\&T, a General Motors ou algum outro gigante empresarial; finalmente, escrevem um livro.

É de se esperar que, para pesquisadores e acadêmicos, estes livros sejam tão importantes como um Harold
Robbins ou um Paulo Coelho para a literatura de ficção. Mas, muitos dos autores têm por trás de si uma longa vida acadêmica. Outros acumularam grande experiência prática em consultoria ou através de contatos de toda natureza com empresas de médio e grande porte.

É o caso de Ralph Kilmann, professor de Administraçăo de Empresas e Diretor do Programa de Cultura Corporativa na Joseph M. Katz Graduate School of Business, da Universidade de Pittsburgh. Prestou consultoria a grandes organizaçöes norte-americanas como Ford, General Eletric, TRW, General Foods e Westing. house, tendo publicado artigos e livros sobre temas relacionados à estratégia, estrutura, cultura e mudança organizacional.

Não se assuste o leitor com o esdrúxulo título ou como subtitulo um pouco apelativyo da tradução brasileira. "Gerenciando sem recorrer a soluçôes paliativas" é um bom livro. Kilmann consegue, numa linguagem razoavelmente simples, de leitura fluida, sintetizar pontos vitais para a correta compreensão do processo de mudança organizacional. A razão do título é justamente tornar clara a posição do autor contra a maré de modismos que tem caracterizado a administraçẵo nos últimos anos.

No primeiro capítulo, Kilmann define os princípios e práticas-chave para o processo de mudança. $O$ ponto de partida é o conceito de que o mundo organizacional năo pode mais ser compreendido como uma simples máquina. Nem mesmo a imagem de um sistema aberto seria mais adequada como metáfora para a organização. Para o autor, a organizaçăo moderna só pode ser compreendida como uma rede complexa de relacionamentos interpessoais e intergrupais. Para representá-la, ele propöe a imagem de um holograma complexo.

A partir deste conceito, desenvolve o tipo de abordagem que deve ser o mais adequado para enfentar os problemas organizacionais. Para explicá-la, Kilmann contrapõe sistematicamente princípios relacionados ao paradigma anterior - organizações como máquinas - ao novo - organizações como hologramas complexos. Desta forma, ele diferencia problemas simples de complexos, abordagens isoladas de abordagens múltiplas, gerenciamento participativo de gerenciamento top-to-dow $\mathrm{e}_{\mathrm{z}}$ finalmente, comprometimento com o sucesso de soluções paliativas.

No segundo capítulo, o autor descreve os estágios importantes para a execução de uma mudança planejada. Kilmann propốe um processo com cinco estágios essenciais:

1) inicio do programa, com escolha da unidade ou área na qual a pilotagem será realizada e a definição do grupo de trabalho; 
2) diagnóstico dos problemas, quando o consultor, ou seu equivalente, realiza uma série de entrevistas com membros da organização para definir os fatores de sucesso e os obstáculos existentes;

3) programação das trilhas, com a elaboração de um cronograma para a execução das cinco trilhas de mudança;

4) implantação das trilhas, quando cada uma delas é executada, de forma flexível e com permanente adaptação do processo;

5) avaliação dos resultados, com a realização de uma série de medidas sobre as variáveis que se pretende mudar ou que refletem a mudança;

Globalmente, o processo visa a uma mudança de patamar organizacional; ou seja, criar uma nova forma de pensar e viver a organização, uma nova maneira de fazer frente aos desafios ambientais. Após sua execução, como conseqüência, deve surgir uma nova forma de gerenciar a complexidade.

Os capítulos seguintes descrevem detalhadamente as trilhas mencionadas:

O capítulo 3 fala da Trilha da Cultura. A mudança cultural seria a primeira a ser trabalhada e pré-condição para as trilhas seguintes. Segundo o autor, toda organização possui uma característica invisível, uma forma de fazer as coisas, uma cultura, que determina seu êxito ou seu fracasso. Um método de intervenção cultural em cinco etapas é, então, proposto:

1) explicitação das normas efetivas da organização;

2) estabelecimento das normas desejadas;

3) identificação das contradições culturais;

4) eliminação das contradições culturais; $e$

5) manutenção da mudança cultural.

No capítulo 4, o tema é o Gerenciamento de Problemas Complexos; ou, como treinar líderes nas habilidades necessárias a esta tarefa. $\mathrm{O}$ importante é fazer frente ao que o autor chama de "conspiração da panacéia", a aplicação de soluções simplistas por gerentes pouco experientes ou tecnocratas com uma visão mecanicista do mundo. A proposta é desenvolver as habilidades necessárias à resolução de problemas complexos. Kilmann explicita, neste capítulo, um ciclo básico para gerenciamento de problemas. A correta apreensão dos conceitos implícitos neste ciclo é muito importante para o sucesso organizacional. É na adequação e fundamentação destes conceitos que se situa o sucesso do método. Complementarmente, é apresentada a Tipologia de Personalidades de Jung como forma de sustentação conceitual para a ação gerencial. Ao fim desta trilha, espera-se que os participantes do processo de mudança planejada tenham complementado sua formação conceitual.

A trilha seguinte, da Formação das Equipes, descrita no capítulo 5, trata de como transmitir todo o conhecimento e conceitos vistos nos capítulos anteriores para toda a organização. Dois aspectos principais são tratados: a formação dos grupos de trabalho e a formação da estrutura interequipes. O trabalho dos grupos dá-se em cinco fases:

1) reunião do grupo de trabalho;

2) detecção e definição dos problemas a serem enfocados;

3) geração de soluções e desenvolvimento dos planos de ação;

4) implantação dos planos de ação;

5) monitorização e avaliação dos resultados.

A expectativa para esta fase é a melhoria da qualidade dos processos decisórios e a execução de ações para resolver problemas complexos.

No capítulo 6, a trilha da Estratégia-estrutura, trata da convergência de objetivos, tarefas e pessoas.

Duas perguntas fundamentais devem ser feitas pela organização:

1) para onde estamos indo?

2) como chegaremos lá?

Kilmann propõe a criação de um grupo de funcionários de diversos níveis hierárquicos, denominado Organização de Gerenciamento de Problemas (OGP). Esta estrutura paralela deve trabalhar na solução de problemas complexos de estratégia-estrutura. A primeira etapa, a definição da estratégia, é fundamental para a organização e passa por uma série de fases, da formulação até a síntese de hipóteses.

A etapa seguinte é o alinhamento dos recursos com uma nova estrutura organizacional. Para aproveitar o potencial estratégico, todos os funcionários e recursos devem contar com uma estrutura organizacional para orientar seu tempo e seus esforços. Esta estrutura, que deve ser alinhada, é composta não somente da hierarquia de gerenciamento, mas também dos objetivos a serem atingidos e das tarefas a serem realizadas. Kilmann entende que a mudança é inviável sem a formulação de uma visão e de uma direção dada pela nova estratégia. Além disso, como princípios para uma mudança bem sucedida, são também citados: gradualismo, transparência e participação. A expectativa para esta trilha é colocar a estrutura por trás do plano estratégico, alinhando os recursos da organização na direção certa.

A última trilha, dos Sistemas de Recompensa, é tratada no capítulo 7. A finalidade desta trilha é motivar a alta performance e manter as melhorias.

O autor propõe um outro OGP, estruturalmente análogo ao de estratégia-estrutura, para trabalhar na complexa questão da medição da performance de cada funcionário e da sua colaboração para a performance global da organização. $O$ importe é que o sistema deve recompensar o comportamento no sentido da mudança desejada.

Finalmente, no capítulo 8, Kilmann descreve um caso de 
implantação de seu programa de mudança organizacional, realizado na área de Informaçoes Mercadológicas da Eastman kodak, nos Estados Unidos. Além da possibilidade de acompanhamento prático, passo a passo, da metodologia, é muito interessante, neste capitulo, a narrativa dos problemas e obstáculos enfrentados.

Acredito que Kilmann atinja, em seu livro, o objetivo declarado de produzir uma obra destinada principaimen te a gerentes e executivos em busca de uma maior compreensão dos processos de mudança nas organizações.

Ogrande mérito do autor é ter partido de conceitos bem fundamentados, e, a parti deles, ter desenvolvido um processo global de mudança envolvendo variáveis, normalmente tratadas em separado como cultura, estratégia e estrutura, e, além disso, ter incorporado conceitos relacionados à participação e ao novo perfil de liderança.

Assim, ainda que de forma não aprofundada, quase todos os elementos importantes de um projeto de intervenção são tratados. Infelizmente, Kilmann näo aborda um ponto sem dúvida fundamental, que é a questão dos fluxos de interesse e poder dentro da organização e sua interferência nos processos de mudança.

No processo de mudança organizacional iniciado há seis anos pela Rhodia e conhecido como PRHOEX - Processo Rhodia de Excelência, as idéias de Kilmann têm sido objeto de constante atenção e estudo. Muito da concepçăo e práticas deste processo podem ser encontradas nas páginas deste livro. \&

\section{STRATEGIA DELLE AMMINISTRAZIONE PUBBLICHE}

\section{GIANFRANCO REBORA A MARCO MENECUZZO}

Torino, UTET, 1990, 374 páginas.

Por Tania Mezzomo, Administradora, Mestre em Administraçăo Pública (EAESP/FGV) com aperfeiçoamento na Universitá Bocconi (Milazo) e Haifa University (Israel), Doutoranda em Administraçăo de Empresas (EAESP/FGV) na área de Organizações e Recursos Humanos, Pesquisadora do Centro de Estudos de Administração e Políticas de Governo (EAESP/FGV).

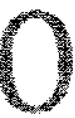

livro Strategia delle Amministrazione Pubbliche foi escrito por Gianfranco Rebora - Professor Titular de Organização do Trabalho nas Administraçôes Públicas da Universitá Statale di Economia di Bréscia e da Universitá Commerciale Luigi Bocconi, Milăo - e Marco Meneguzzo - docente de Economia das Administraçōes Públicas nesta última universidade.

O objetivo do trabalho é desenvolver um conceito de análise e gestão estratégica referido às organizaçôes e às empresas públicas. Olivro é parte integrante de uma obra com vinte publicações planejadas (sete já publicadas), versando sobre direção e gestäo empresarial, escritos por professores das faculdades de Economia e Administração de diversas universidades italianas.

É importante colocar, inicialmente, que este livro articula conceitos teóricos, estreitamente ligados aos depoimentos dos atores envolvidos (políticos e funcionários), experiências concretas e estudos de caso referidos à vária e complexa realidade da Administração Pública Italiana e àquela de outros paises europeus.

O livro, na verdade, foi elaborado partindo da vasta experiência dos autores dentro da Divisão de Administração Pública da Escola de Direzione Aziendale (SDA) uma espécie de MBA adequado à estrutura educacional italiana, diferente da americana - da Universitá Luigi Bocconi. Essa instituição levou a cabo, de modo pioneiro, no contexto italiano do fim dos anos 70 , intervenções de formação administrativa e consultoria de processo destinados a dirigentes e funcionários públicos operantes no governo local, no Serviço Sanitário Nacional e nas empresas municipais de prestaçăo de serviços públicos. ${ }^{2}$

Nos últimos anos, em preparação à criação do Mercado Único Europeu, que terá um impacto específico sobre o setor público (mobilidade dos funcionáríos, mudança nos procedimentos de aquisição de bens e serviços, alteraçăo de aliquotas fiscais), a Divisẵo de Administraçâo Pública da SDA levou a cabo uma série de pesquisas destinadas a compreender a problemática organizativa e gerencial de outras administraçōes européias, pesquisas cujos resultados foram em parte retomados no livro.

Com o objetivo de apresentar aos leitores brasileiros este trabalho, é oportuno colocar duas questöes de fundo.

A primeira é relativa a entender porque uma reflexão sobre a Administração Pública Italiana, que constitui um modelo de burocracia fechada, aparentemente estranha às influências do ciclo politico, operante em um sistema sócioeconômico que viveu nos últimos anos uma relativa expansão e uma baixa inflaçăo, pode interessar ao contexto brasileiro.

O caso brasileiro, contrariamente, registra a presença de um modelo de burocracia aberta, fortemente influenciado por uma constante mudança dos atores politicos e de uma elevada dinâmica inflacionária que amplifíca a necessidade de gestăo "dia-a-dia". Ainda, a Administração Pública brasileira é sujeita a uma pesada (e maquiavélica) regulamentação jurídico-administrativa e deve responder a um desafio duplo: "desprivatizar o estado" e criar "uma cultura de governo" que torne o aparelho administrativo mais eficiente e transparente. ${ }^{3}$

Não obstante ${ }_{f}$ por trás desta aparente diferença, existem inúmeros pontos de contato, especialmente no que se refere à cultura organizacional que sustenta a Administração Pública nos dois países.

A segunda questão de fundo refere-se a qual seria o espaço efetivo para que se possa introduzir critérios e ló- 